\title{
Physiological risk of falls, physical and aerobic capacity in community-dwelling elderly
}

\author{
Risco fisiológico de quedas, capacidade física e aeróbica em \\ idosos comunitários
}

\section{Lygia Paccini Lustosa [i] ${ }^{[a]}$, Jederson Soares da Silva (iD [a,b], Danielle Aparecida Gomes Pereira (D)[a], Marcella Guimarães Assis [i] [a], Leani Souza Máximo Pereira (iD][a]*}

[a] Universidade Federal de Minas Gerais (UFMG), Belo Horizonte, MG, Brazil

[b] Faculdade Pitágoras, Betim, MG, Brazil

\section{Abstract}

Introduction: Falls are multifactorial and are related to the aging process, reduced functional capacity, comorbidities, sensory deficits, muscle weakness, postural instability and decreased protective response. Objective: To verify the correlation between physiological risk of falls and physical and aerobic capacity of the community-dwelling elderly. Method: Participated elderly individuals from the community, aged $\geq 65$ years, without distinction of sex, race, and/or social class. We excluded cognitive impairments, locomotion incapacity, neurological diseases or sequelae, and/or severe pain that prevented the performance of the tests. We evaluated risk of falls (Physiological Profile Assessment - PPA), physical capacity (Short Physical Performance Battery - SPPB) and aerobic capacity (Shuttle Walk Test - ISWT). Results: Participated 59 elderly (71.8 \pm 5.0 ys). The mean performance in PPA was $0.4 \pm 0.4$; SPPB was $10.4 \pm 1.7$ and ISWT was $281 \pm 111.7$ meters. PPA presented a moderate and statistically significant correlation $(\mathrm{P}<0.001)$ for $\mathrm{SPPB}$ $(r=-0.53)$ and ISWT $(r=-0.46)$. Conclusion: There is a moderate correlation between the physiological risk

*LPL: PhD, email: lygiapl@ufmg.br

JSS: MS, email: jedersonsoares@yahoo.com.br DAGP: PhD, email: danielleufmg@gmail.com MGA: PhD, email: marcellagassis@gmail.com LSMP: PhD, email: leanismp.bh@terra.com.br 
of falls (PPA) and functional (SPPB) and aerobic capacity (ISWT). Preventive measures to reduce the risk of falls should include strategies to increase functional and aerobic capacity. It is suggested the systematic use of SPPB in clinical practice.

Keywords: Accidental Falls. Aged. Physical Functional Performance.

\section{Resumo}

Introdução: Quedas são multifatoriais e estão relacionadas com o processo de envelhecimento, redução da capacidade funcional, presença de comorbidades, déficits sensoriais, fraqueza muscular, instabilidade postural e redução da resposta protetora. Objetivo: Verificar a correlação entre risco fisiológico de quedas e capacidade física e aeróbica em idosos comunitários. Método: Participaram idosos da comunidade, com 65 anos e mais, sem distinção de sexo, raça e/ou classe social. Excluiu-se aqueles com déficit cognitivo, incapacidade de locomoção, doenças e sequelas neurológicas e, dor que incapacitasse a realização dos testes. Avaliou-se risco de quedas (Physiological Profile Assessment - PPA), capacidade física (Short Physical Performance Battery - SPPB) e capacidade aeróbica (Incremental Shuttle Walk Test - ISWT). Resultados: Participaram 59 ido-

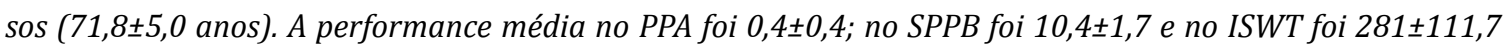
metros. PPA apresentou uma negativa, moderada e estatisticamente significante correlação $(p<0.001)$ com o SPPB $(r=-0,53)$ e ISWT $(r=-0,46)$. Conclusão: Medidas preventivas para reduzir o risco de quedas devem incluir estratégias para aumentar capacidade funcional e aeróbica. Sugere-se ainda, o uso do SPPB na prática clínica, como medida de rastreio.

Palavras-chave: Acidentes por Quedas. Idoso. Desempenho Físico Funcional.

\section{Introduction}

Falls can be defined as unintended movements to a lower level than the level a person was at previously $[1,2]$. The World Health Organization states that approximately $28-35 \%$ of elderly people over 65 years suffer at least one fall per year [3]. Their causes are multifactorial and closely related to the aging process, due to reduced functional capacity, presence of comorbidities, sensorial and visual deficits, muscle weakness, postural instability, and increased protection response time [3-5].

Thus, falls are considered one of the biggest public health problems for the elderly population, being responsible for the high social and economic cost for the country [1-5]. The elderly who fall are subject to deleterious, physical, psychological, and social consequences $[4,5]$. The literature points several negative health outcomes as a consequence of falls [1-5]. In addition, depression and increased restriction of activities and mobility may occur, as well as increased mortality [4].

Similarly, loss of functional and aerobic capacity has also been reported in the literature, with the aging process. In fact, these phenomena are widely studied as it has been shown to be associated with various health outcomes [1-5]. However, there is still no evidence of single causal factor. Most of the time, an association of these outcomes is pointed out and this interrelation between functionality and falls can help identify important factors for the prevention of falls $[4,5]$.

Therefore, changes in functionality may contribute to various health outcomes and may be considered markers for aging. It is known that elderly people with functional loss eventually become more dependent and increasing costs with health and care. In addition, the greater dependence ends up contributing to a lower quality of life [4-6].

Besides this, age-related physiological changes in the cardio respiratory system associated with physical inactivity may result in complications, such as postural hypotension, cardiac arrhythmias, weakness, and dizziness, causing changes during gait, loss of balance, increasing the fall risk and compromising the individual's functionality of the cardio respiratory system $[7,8]$. In this context, previous studies have shown that older people with poor performance 
on the SPPB have more falls $[9,10]$. However, no studies evaluated the correlation between SPPB and the physiological risk of falls (measured by the PPA) in the Brazilian elderly population. Moreover, despite the evidence that falls have a great impact on functionality, information regarding the relationship with aerobic capacity is still scarce, particularly in the Brazilian population, especially when considering the physiological risk.

In this context, the aim was to verify the correlation between physiological risk of falls, the physical and aerobic capacity in the elderly community.

\section{Method}

This is an exploratory cross-sectional observational study, part of the multicenter project approved by the research ethics committee of the institution under the protocol CAAE 14129513.7.1001.5149. The convenience sub-sample comprised elderly individuals from the community, aged $\geq 65$ years, without distinction of sex, race, and/or social class. The elderly who agreed to participate in the study signed the informed consent form.

We excluded the elderly with cognitive impairments evaluated through the Mini-Mental State Examination according to the level of education [11]. Elderly people with locomotion incapacity, neurological diseases or sequelae, and/or severe pain that prevented the performance of the tests were also excluded.

\section{Measuring instruments}

To characterize the sample population, a structured questionnaire was used by the researchers with sociodemographic data, life habits, and functional information.

\section{Physical capacity}

The Short Physical Performance Battery (SPPB) is an assessment that can be used to evaluate a person's physical capacity with a combination of tests evaluating domains of balance, lower limb strength, and gait speed. The SPPB as being predictive of the health status, functional capacity, hospitalization, institutionalization, and mortality of the individual and is also suggestive of fall risk $[9,12,13]$. This battery of tests is simple, without financial burden, and can be performed at clinics, hospitals, or homes. The SPPB already validated for the Brazilian population, was used $[10,12]$. The score of each test ranges from 0 to 4 points and the total score was obtained by adding the scores of each test, ranging from 0 for worst performance and 12 for best performance. The SPPB scores between 0 and 3 points indicate inability or very poor performance; 4 to 6 points indicate poor performance; 7 to 9 points indicate moderate performance; and 10 to 12 points indicate good performance $[10,12]$.

\section{Aerobic capacity}

The Incremental Shuttle Walk Test (ISWT) is a test capable of assessing sub maximal efforts of the individual, is easy to perform and use in clinical practice, presents reliable results, and has been validated to evaluate aerobic capacity in the Brazilian elderly population [14-17]. Their low performance was associated with a reduction in balance [18]. The individual is instructed to walk a 10-meter flat course containing a cone at each end and then is instructed to increase his/her speed after the beep. Interruption of the test occurs in case of fatigue, limiting pain, heart rate (HR) increase of $85 \%$ of maximum HR, or in the case in which the participant fails to reach two cones consecutively. The results are reported by the distance traveled and the time spent in performing the test $[15,16,19]$.

Fall risk

The Physiological Profile Assessment (PPA) is a tool which is considered to be the gold standard for measuring and identifying the physiological risk of falls in the elderly with 75\% accuracy [6]. Previous studies have shown good reliability in evaluating the physiological risk of falls in the Brazilian elderly population [20]. We used the short version of the PPA [6] which consists of five tests: sensitivity to visual contrast as measured by the Melbourne Edge Test, proprioception as measured by the alignment of the lower limbs on a millimeter acrylic board, muscle strength of the knee extensors by means of a mechanical dynamometer, and reaction time (in milliseconds) of the hand using an electronic timer that was triggered by pressure on a mouse when a red light came on (Figure 1). Postural oscillation was 
measured using an oscillometer attached to the waist of individuals who were standing on a foam board $[6,20]$.

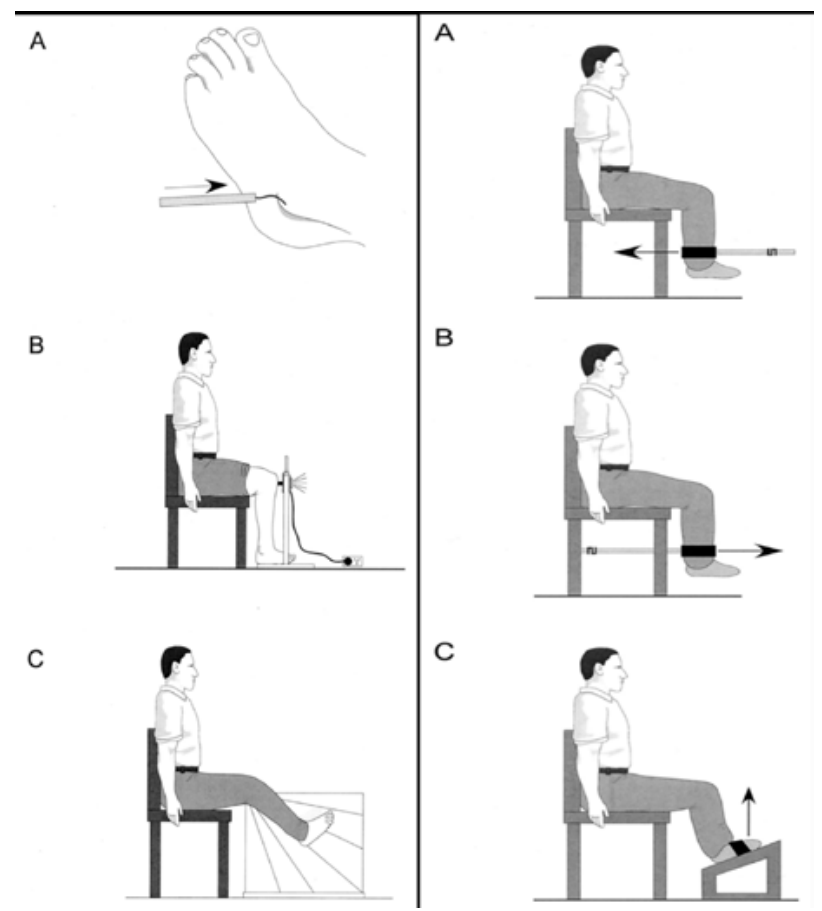

Figure $\mathbf{1}$ - Tests that make up the Physiological risk of falls (PPA) - proprioception as measured by the alignment of the lower limbs on a millimeter acrylic board; muscle strength of the knee extensors by means of a mechanical dynamometer. Note: Adapted from Lord et al. [6].

Results of the five tests were entered into a software program (Fall Screen ${ }^{\circledR}$ ) and adjusted for the sex and age of the participant compared and normalized using data from previous large-scale studies. The program calculates the fall risk using an algorithm. The tests and their psychometric properties were validated as good psychometric properties [6]. After the analysis, the results were presented in graph form indicating the classification of the overall physiological risk of falls and their performance on each test. The overall score indicating the physiological risk of falls is: $<0$ low; $0-1$ mild; $1-2$ moderate; and $>2$, high fall risk $[6,20]$.

\section{Statistical analysis}

The number of participants in the sample was based on previous studies with the physiological risk of falls of the elderly in the community, where a pilot study was carried out with 10 healthy individuals. Using the mean and standard deviation of the results, the effect size index values (d) were calculated for each variable. The significance level 0.05 was used, and estimated sample sizes for the Power values were equal to 0.80 . According to the effect size calculation, the domain that presented the smallest magnitude and consequently, the largest sample size, was the fall risk. Therefore, this domain was used as the reference for estimating the study sample size. The number of participants (n) for the study was 52 individuals [21]. The descriptive analysis was used to characterize the sample. The normality of the data was verified using the Shapiro Wilk test. The correlation between the variables was made by the Pearson correlation coefficient for the data with normal distribution and Spearman's test for data with non-normal distribution. The significance level considered for the variables was $5 \%$ with a $95 \%$ confidence interval. The Statistical Package for the Social Sciences-SPSS (IBM SPSS Data Collection) version 19.0 was used.

\section{Results}

Fifty-nine community-dwelling elderly (aged $71.8 \pm 5.0$ years) participated; mean schooling was $6.8 \pm 4.1$ years of study. Mean number of medications used was $3.8 \pm 2.7$. Table 1 shows other sociodemographic data of the sample and life habits.

Table 1 - Descriptive analysis of the sample of communitydwelling elderly participants $(n=59)$

\begin{tabular}{lcc}
\hline \multicolumn{1}{c}{ Variable } & Frequency & $\begin{array}{c}\text { Percentage } \\
(\%)\end{array}$ \\
\hline Sex & 52 & 88.1 \\
Female & 7 & 11.9 \\
Male & & \\
Civil state & 22 & 37.3 \\
Married & 14 & 23.7 \\
Single & 5 & 8.5 \\
Divorced & 18 & 30.5 \\
Widow (er) & & \\
Education & 3 & 5.1 \\
illiterate & 24 & 40.7 \\
1 to 4 years & 17 & 28.8 \\
5 to 8 years & 9 & 15.3 \\
9 to 12 years & 6 & 10.2 \\
More than 12 years & & \\
Lives with & &
\end{tabular}

(to be continued) 


\begin{tabular}{lcc}
\hline & & (conclusion) \\
Spouse & 22 & 37.3 \\
Children or stepchildren & 19 & 32.2 \\
Alone & 10 & 16.9 \\
Grandchildren & 1 & 1.7 \\
Other relatives & 6 & 10.2 \\
People outside the family & 1 & 1.7 \\
Smoking & & \\
No & 57 & 96.9 \\
Yes & 2 & 3.4 \\
Alcoholism & & \\
No & 43 & 72.9 \\
Yes & 16 & 27.1 \\
Physical activity & & \\
No & 30 & 50.8 \\
Yes & 29 & 49.2 \\
Subjective well- \\
being of health \\
Good health
\end{tabular}

Note: time since stroke in months (T Stroke); body mass index (BMI); Barthel's index (BI); Mini-Mental State Examination (MMSE); peak expiratory flow L/min (PEF); maximum inspiratory pressure in $\mathrm{cmH}_{2} \mathrm{O}$ (MIP); maximum expiratory pressure in $\mathrm{cmH}_{2} \mathrm{O}$ (MEP), IBI expiratory peak (E-IBI); IBI inspiratory peak (I-IBI); standard deviation (SD); n: total sample.

Regarding the classification for the physiological risk of falls evaluated by the PPA, $44.1 \%$ of the sample presented a mild physiological risk of falls, and only $3.4 \%$ of the participants presented a marked fall risk. The overall mean score in the PPA scores was $0.4 \pm 0.4$. Table 2 shows performance on the subtests.

Most of the elderly had a good performance on the SPPB (76.3\%), with a mean of $10.4 \pm 1.7$ (range, 6-12 points). The worst performance presented by the elderly in the SPPB was on the chair stand and sit test with an average of $2.9 \pm 1.1$ points. The average distance traveled by participants in the ISWT was $281 \pm 111.7$ meters; mean time to perform the test was $5.18 \pm 1.31$ minutes (Table 3 ).

After the correlation analysis, it was found that the SPPB and ISWT tests had a moderate and significant association with PPA (Table 4).
Table 2 - Classification of the elderly regarding the Physiological Global Falls Risk and the performance in the tests evaluated by the PPA $(n=59)$

\begin{tabular}{|c|c|c|}
\hline \multicolumn{3}{|c|}{ PPA - Final classification } \\
\hline Classification & Frequency & Percentage (\%) \\
\hline Low & 20 & 33.9 \\
\hline Mild & 26 & 11.9 \\
\hline Moderate & 11 & 18.6 \\
\hline \multirow[t]{2}{*}{ High fall risk } & 2 & 3.4 \\
\hline & Mean & $\begin{array}{l}\text { Standard } \\
\text { deviation }\end{array}$ \\
\hline Score - Global Fall risk & 0.4 & 0.4 \\
\hline \multicolumn{3}{|l|}{ Tests assessed by PPA } \\
\hline Vision (dB) & $20.3(19-24)^{*}$ & 2.3 \\
\hline Proprioception $\left({ }^{\circ}\right)$ & $2.0(0,6-2.8)^{*}$ & 1.0 \\
\hline Postural Sway (mm) & $109.7(68-178)^{\star}$ & 50.7 \\
\hline Reaction time (ms) & $252.6(195-265)^{\star}$ & 40.8 \\
\hline Quadriceps strength (kg) & $22.0(18-33)^{\star}$ & 40.8 \\
\hline
\end{tabular}

Table 3 - Results of the performance of the elderly in SPPB and ISWT $(n=59)$

\begin{tabular}{|c|c|c|}
\hline \multicolumn{3}{|c|}{ SPPB - Short Physical Performance Battery } \\
\hline Subtests SPPB & Mean & $\begin{array}{l}\text { Standard } \\
\text { deviation }\end{array}$ \\
\hline SPPB - Balance & 3.6 & 0.7 \\
\hline SPPB - Gait speed & 3.8 & 0.5 \\
\hline SPPB - Stand up and sit & 2.9 & 1.1 \\
\hline SPPB - Total & 10.4 & 1.7 \\
\hline \multicolumn{3}{|c|}{ ISWT - Incremental Shuttle Walk Test } \\
\hline & Mean & $\begin{array}{l}\text { Standard } \\
\text { deviation }\end{array}$ \\
\hline Gait distance (m) & 281.0 & 111.7 \\
\hline Total time (min) & 5.2 & 1.3 \\
\hline
\end{tabular}

Note: m: meters; min: minutes.

Table 4 - Correlation analysis between PPA x SPPB and PPA x ISWT

\begin{tabular}{lcc}
\hline \multirow{2}{*}{ Variables } & \multicolumn{2}{c}{ PPA - Total } \\
\cline { 2 - 3 } & $\mathrm{r}$ & $\mathrm{P}$ \\
\hline SPPB - Total & 3.6 & 0.7 \\
SPPB - Balance & 3.8 & 0.5 \\
SPPB - Gait speed & 2.9 & 1.1 \\
SPPB - Stand up and sit & 10.4 & 1.7 \\
ISWT - Gait distance & $\mathbf{- 0 . 4 6 * * *}$ & $<\mathbf{0 . 0 0 1 *}$ \\
ISWT - Total time & $\mathbf{- 0 . 4 6 * * *}$ & $<\mathbf{0 . 0 0 1 *}$ \\
\hline
\end{tabular}

Note: * Statistically significant correlation $\mathrm{P}<0.01$; ${ }^{*}$ Spearman's test; *** Pearson's correlation test; PPA: Physiological Profile Assessment; SPPB: Short Physical Performance Battery; ISWT: Incremental Shuttle Walk Test. 


\section{Discussion}

As a fall is multifactorial in nature, this study aimed to verify if any of the tests chosen with different assessments, one of physical capacity (SPPB) and one of aerobic capacity (ISWT), had a correlation with the physiological risk of falls (PPA) in the community-dwelling elderly. The results showed that both tests had a moderate and significant correlation with PPA. Most of the elderly participants were women, with up to four years of schooling, did not use tobacco and alcohol, reporting good health. The same proportion of elderly people was married or widowed. These characteristics are in agreement with the literature, when they describe the Brazilian elderly [21].

Another important result was that most of the elderly self-participants reported not having fallen in the last six months. The Ministry of Health reports that we have a $30 \%$ rate of elderly falls in our country, based on population studies [3]. However, in our study, the rate of the elderly who fell in the last six months was $18.6 \%$, a lower number than that established by this agency $[3,4]$. However, the present study was not of the population epidemiological type but of a small sample of convenience, which limits the generalization of the results. Additionally, the time for reporting of falls was only 6 months. This fact may explain the difference found. On the other hand, the choice of using specific evaluation devices justifies smaller samples, supported by the sample calculation.

Thus, a mild physiological risk for falls was found in $44.1 \%$ of the participants and only $3.4 \%$ of the elderly presented a marked fall risk. A result that is similar to the overall mean of Australian community-based older women in another study [22,23], and previous studies that also used the PPA as an identifier of the physiological risk of falls in elderly patients presenting with comorbidities corroborate our results. Rosa et al. [21] evaluated 104 Brazilian community-dwelling elderly individuals with or without low back pain; the overall PPA mean for the group without back pain was $0.5 \pm 0.8$. For those with low back pain, this index increased to $1.6 \pm 0.7$, with the conclusion that low back pain influences the physiological risk of falls. In this case, one might think that specific conditions may influence the physiological risk of falls, which was not demonstrated in this study. The elderly participants in this study had no specific conditions reported; only the physiological process of aging, controlled, and compensated comorbidities.
Few studies have been conducted to verify the performance of the elderly on SPPB and its association with falls. Ward et al. [24] performed a longitudinal prospective study with a mean follow-up of 2.4 years with 755 elderly community-dwelling Americans (aged 78.1 \pm 5.4 years) and assessed whether physical performance assessed by the SPPB was predictive of falls. The authors concluded that $29 \%$ of the studied sample had at least one episode of falling and that the low performance on the SPPB would not be a predictor of falls, but a score over 16.7 seconds, classified as 1 point, for the subtest of sitting and getting up from the chair for five repetitions proved to be an independent predictor [24]. In our study, the sitting and getting up test was also the sub-test of the SPPB on which the elderly exhibited their worse performance. It is worth mentioning that the elderly who scored less than 3 points performed the sit and stand test with times greater than 13.7 seconds. These values are close to the predictive fall score proposed by Ward et al. [24].

Similarly, Veronese et al. [25] verified the association between SPPB performance $(8.4 \pm 3.17)$ and previous history of falls in 2710 community-dwelling elderly (aged 75.5 \pm 7.4 years) from Padova, Italy in an observational cohort study. The authors concluded that lower SPPB scores were associated with a higher rate of falls and that the test proved to be a reliable tool in the evaluation of falls among the elderly. Mangani et al. [26], in a prospective cohort study, evaluated the history of falls using the SPPB in 364 elderly communities (aged $85.9 \pm 4.9$ years) from Florence, Italy and also concluded that the low physical performance was associated with the occurrences of falls among the elderly studied. Our results are in agreement with these authors in the same way as with the results of Singh et al. [14] that also correlated the SPPB with the physiological risk of falls assessed by PPA. The authors evaluated 140 Malaysian community-dwelling women stratified into groups of high $(\mathrm{n}=18)$ and low fall risk $(\mathrm{n}=122)$ (at age $68.3 \pm 4.4$ and $65.7 \pm 4.5$ years, respectively). They found a significant negative correlation between the physiological risk of falls with the SPPB ( $r=-0.33 ; \mathrm{P}>0.01)$ and that the sit-up sub-test of the SPPB showed a higher correlation with the PPA tests [14]. Conversely, the SPPB is a multi-domain test, it allows the health professional to check and choose which of these domains, gait, balance, and muscle strength are deficient, allowing directed treatment to reduce the physiological risk of falls in the elderly. 
In our study, the mean walking distance by the ISWT was $281 \pm 111.7$ meters, lower than the mean for Brazilian elderly people, which was approximately $467 \pm 147$ meters [17]. This result showed that most of the elderly participants in the study had a low cardio respiratory capacity. Morales et al. [27] demonstrated that results below 450 meters are associated with a worse prognosis and are also predictive of cardiac events. Although $49.2 \%$ of the participants reported being a physical activity practitioner, a reduction of lower limb muscle strength was observed in our sample and some tests were interrupted because they reached $85 \%$ of maximal heart rate; these factors may have influenced the poor performance on the ISWT.

Some previous studies have associated the performance of the elderly on the ISWT and the occurrence of falls, but not the risk of falling. Bardin et al. [18] associated the performance on the ISWT with the occurrence of falls in a sample of elderly women (aged 68 \pm 7 year). The mean ISWT performance was $313 \pm 79$ meters for the elderly fall group in the last year and $395 \pm 75$ meters for elderly women with no history of falls. Hayashi et al. [28] verified whether different levels of postural balance were associated with different levels of aerobic capacity assessed by the ISWT in 157 elderly individuals over 60 years old living in Londrina, Brazil. The study concluded that the elderly with better aerobic capacity had a better postural balance. No previous studies were found that correlated the ISWT with the PPA. However, based on the results of this study that showed that those with better aerobic capacity had lower risk of falls, it can be thought that the practice of this type of activity may be preventive for falls.

A limitation of this study is that it was a convenience sample, which cannot be extrapolated to non-community-dwelling elderly individuals or those who presented with some comorbidities in the exclusion criteria of the study. Falls are multifactorial events and the study did not evaluate the extrinsic or intrinsic factors through complementary tests; only laboratory tests were performed $[29,30]$. The type, duration, and intensity of exercise were not reported by the elderly practicing physical activity.

\section{Practical Application}

The SPPB evaluates a greater number of domains involved in falls, being that the stand up and sit domain of the chair test was the one that obtained the highest correlation with the physiological risk of falls.
Based on the assumption that falls are multifactorial events and that their physiological risk is also multifactorial, it is possible to deduce that the more domains are evaluated as proposed by the SPPB, the greater the chances of detecting fall risk in the elderly [30]. Thus, it is suggested the systematic use of SPPB in clinical practice.

\section{Conclusion}

Our results demonstrated that there is a moderate correlation between the physiological risk of falls (PPA) and functional (SPPB) and aerobic capacity (ISWT). The worst performance of the elderly in the SPPB and ISWT would be an alert for fall risk in the elderly, allowing physical therapists preventive and rehabilitation measures.

\section{References}

1. Sherrington C, Tiedemann A. Physiotherapy in the prevention of falls in older people. J Physiother. 2015;61(2):54-60.

2. American Geriatrics Society, British Geriatrics Society. Summary of the Updated American Geriatrics Society/ British Geriatrics Society clinical practice guideline for prevention of falls in older persons. J Am Geriatr Soc. 2011;59(1):148-57.

3. World Health Organization. WHO Global Report on Falls Prevention in Older Age. 2007 [cited 2019 jul 01]. Available from: https://tinyurl.com/yacdyhxb

4. Perracini MR, Ramos LR. Fall-related factors in a cohort of elderly community residents. Rev Saude Pub. 2002;36(6):709-16.

5. Kenny RA, Rubenstein LZ, Tinetti ME, Brewer K, Cameron KA, Capezuti EA, et al. Summary of the updated American Geriatrics Society/ British Geriatrics Society Clinical practice guideline for prevention of falls in older persons. Panel on prevention of falls in older persons. J Am Geriatr Soc. 2011;59(1):148-57.

6. Lord SR, Menz HB, Tiedemann A. A Physiological Profile Approach to Falls Risk Assessment and Prevention. Phys Ther. 2003;83(3):237-52. 
7. Hernandes NA, Probst VS, Silva Jr RA, Januário RSB, Pitta F, Teixeira DC. Physical activity in daily life in physically independent elderly participating in community-based exercise program. Braz J Phys Ther. 2013;17(1):57-63.

8. Gomes-Neto M, Araújo AD, Junqueira IDA, Oliveira D, Brasileiro A, Arcanjo FL. Comparative study of functional capacity and quality of life among obese and non-obese elderly people with knee osteoarthritis. Rev Bras Reumatol. 2016;56(2):126-30.

9. Studenski S, Perera S, Wallace D, Chandler JM, Ducan PW, Rooney E, et al. Physical Performance Measures in the Clinical Setting. J Am Geriatr Soc. 2003;51(3):314-22.

10. Guralnik JM, Seeman TE, Tinetti ME, Nevitt MC, Berkman LF. Validation and use of performance measures of functioning in a nondisabled older population: MacArthur Studies of Successful Aging. Aging Clin Exp Res. 1994;6(6):410-9.

11. Bertolucci PHF, Brucki SMD, Campacci SR, Juliano Y. The Mini-Mental State Examination in an outpatient population: influence of literacy. Arq Neuropsiquiatr. 1994;52(1):1-7.

12. Nakano MM. Brazilian version of Short Physical Performance Battery -SPPB: Cultural adaptation and reliability study [master's degree]. Campinas: Universidade Estadual de Campinas; 2007.

13. Guralnik JM, Ferrucci L, Pieper CF, Leveille SG, Markides KS, Ostir GV, et al. Lower Extremity Function and Subsequent Disability: Consistency across studies, predictive models, and value of gait speed alone compared with the Short Physical Performance Battery. J Gerontol A Biol Sci Med Sci. 2000;55(4):M221-31.

14. Singh DKA, Pillai SGK, Tan ST, Tai CC, Shahar S. Association between physiological falls risk and physical performance tests among community-dwelling older adults. Clin Interv Aging. 2015;13(10):1319-26.

15. Dourado VZ, Guerra RLF, Tanni SE, Antunes LCO, Godoy I. Reference values for the incremental shuttle walk test in healthy subjects: from the walk distance to physiological responses. J Bras Pneumol. 2013;39(2):190-7.

16. Monteiro DP, Britto RR, Carvalho MLV, Montemezzo D, Parreira VF, Pereira DAG. Shuttle walking test as an instrument for assessment of functional capacity: a literature review. Cienc Saude. 2014;7(2):92-7.

17. Jürgensen SP, Antunes LC, Tanni SE, Banov MC, Lucheta PA, Bucceroni AF, et al. The Incremental Shuttle Walk Test in Older Brazilian Adults. Respiration. 2011;81(3):223-8.
18. Bardin MG, Dourado VZ. Association between the occurrence of falls and the performance on the Incremental Shuttle Walk Test in elderly women. Rev Bras Fisioter. 2012;16(4):275-80.

19. Singh SJ, Morgan MD, Scott S, Walters D, Hardman AE. Development of a shuttle walk test of disability in patients with chronic airways obstruction. Thorax. 1992;47(12):1019-24.

20. Sampaio NR, Rosa NMDB, Godoy APS, Pereira DS, Hicks S, Lord SR, et al. Reliability Evaluation of the Physiological Profile Assessment to Assess Fall Risk in Older People. J Gerontol Geriat Res. 2014;3(5):179.

21. Rosa NMB, de Queiroz BZ, Lopes RA, Sampaio NR, Pereira DS, Pereira LSM. Risk of falls in Brazilian elders with and without low back pain assessed using the Physiological Profile Assessment: BACE study. Braz J Phys Ther. 2016;20(6):502-9.

22. Szabo SM, Jansen PA, Khan K, Potter MJ, Lord SR. Older women with age-related macular degeneration have a greater risk of falls: a physiological profile assessment study. J Am Geriatr Soc. 2008;56(5):800-7.

23. Lord SR, Ward JA, Williams P, Anstey KJ. Physiological factors associated with falls in older community-dwelling women. J Am Geriatr Soc. 1994;42(10):1110-7.

24. Ward RE, Leveille SG, Beauchamp MK, Travison T, Alexander N, Jette AM, et al. Functional performance as a predictor of injurious falls among older adults. J Am Geriatr Soc. 2015;63(2):315-20.

25. Veronese N, Bolzetta F, Toffanello ED, Zambon S, De Rui M, Perissinotto E, et al. Association between short physical performance battery and falls in older people: the progetto Veneto Anziani study. Rejuvenation Res. 2014;17(3):276-84.

26. Mangani I, Cesari M, Russo A, Onder G, Maraldi C, Zamboni $V$, et al. Physical function, physical activity and recent falls. Results from the "Invecchiamento e Longevità nel Sirente (ilSirente) Study". Aging Clin Exp Res. 2008;20(3):234-41.

27. Morales FJ, Montemayor T, Martinez A. Shuttle versus six-minute walk test in the prediction of outcome in chronic heart failure. Int J Cardiol. 2000;76(2-3):101-5.

28. Hayashi D, Gonçalves CG, Parreira RB, Fernandes KB, Teixeira DC, Silva RA, et al. Postural balance and physical activity in daily life (PADL) in physically independent older adults with different levels of aerobic exercise capacity. Arch Gerontol Geriatr. 2012;55(2):480-5. 
29. Park SH. Tools for assessing fall risk in the elderly: a systematic review and meta-analysis. Aging Clin Exp Res. 2018;30(1):1-16.
30. Lusardi MM, Fritz S, Middleton A, Allison L, Wingood M, Phillips E, et al. Determining risk of falls in communitydwelling older adults: a systematic review and metaanalysis using posttest probability. J Geriatr Phys Ther. 2017;40(1):1-36.

Received: 01/08/2019

Recebido: 08/01/2019

Approved: : 04/14/2020

Aprovado: $14 / 04 / 2020$ 